\title{
Meteorologically forced subinertial flows and internal wave generation at the main sill of the Strait of Gibraltar
}

\author{
Agueda Vázquez ${ }^{a}$, Miguel Bruno ${ }^{a, *}$, Alfredo Izquierdo ${ }^{a}$, \\ Diego Macías ${ }^{\mathrm{b}}$, Antonio Ruiz-Cañavate ${ }^{\mathrm{a}}$ \\ a Departamento de Física Aplicada, Universidad de Cádiz, 11510 Puerto Real, Cádiz, Spain \\ b Departamento de Biología, Área de Ecología, Universidad de Cádiz, 11510 Puerto Real, Spain
}

\section{A R T I C L E I N F O}

\section{Article history:}

Received 26 December 2007

Received in revised form

5 May 2008

Accepted 14 May 2008

Available online 27 May 2008

\section{Keywords:}

Subinertial flows

Internal waves

Stratified flow

Internal bore

Gibraltar Strait

Internal hydraulic

\begin{abstract}
A B S T R A C T
The generation of large-amplitude internal waves in the Strait of Gibraltar is a widely known phenomenon. Those waves are produced by the interaction of barotropic tidal flow with the main sill (Camarinal Sill) topography and the stratified water column. That interaction primarily causes internal tides that evolve, by non-linear processes, into large-amplitude (more than $100 \mathrm{~m}$ ) internal waves exhibiting much shorter oscillation periods than those related to the basic tidal variability. Recent observations have shown that on many occasions large-amplitude internal wave generation is dependent on the state of the subinertial flows, which are basically driven by the atmospheric pressure fluctuations over the Mediterranean. Therefore, depending on the meteorological situation over the Mediterranean, internal wave events may be inhibited or activated.

(c) 2008 Elsevier Ltd. All rights reserved.
\end{abstract}

\section{Introduction}

Flow variability through the Strait of Gibraltar may be basically categorized into three distinct types: long term, subinertial and tidal (Lacombe and Richez, 1982). The long-term flow exhibits a seasonal and inter-annual variability and relates to the two-layer baroclinic exchange, while subinertial flows, with periods ranging from days to a few months, are mostly barotropic and have been found to be principally forced by the atmospheric pressure fluctuations over the western Mediterranean Sea. Tidal flows are also for the most part of barotropic, at least in the vicinity of the main sill (Camarinal Sill) of the strait (Candela et al., 1990; Bruno et al., 2000). On the other hand, the interaction of this barotropic tidal flow with Camarinal Sill topography and the stratified water column primarily causes internal tides that evolve, by non-linear

\footnotetext{
* Corresponding author. Tel.: +34 956016076; fax: +34 956016079.

E-mail address: miguel.bruno@uca.es (M. Bruno).
}

processes and non-hydrostatic dispersion, into largeamplitude (more than $100 \mathrm{~m}$ ) internal waves exhibiting much shorter period and wavelength than those related to the basic tidal variability (Richez, 1994; Bruno et al., 2002). These internal waves have been found to be one of the major contributors to the mixing between the Atlantic and Mediterranean layers within the Strait (Wesson and Gregg, 1994; Macias et al., 2006), being able to have significant remote effects on the hydrography of the Alboran Sea (Vázquez et al., 2006). This fact confers special importance to the study of internal wave phenomena in the Strait of Gibraltar.

As discussed by Bruno et al. (2002), the trapping of internal waves on the lee side of the sill, is caused by the establishment of critical or supercritical conditions over the sill and it is an important factor explaining the growth in amplitude that internal waves experience there. The release of the internal waves towards the Mediterranean begins with the establishment of subcritical conditions over the sill. It happens almost at the beginning of the inflow phase of the barotropic tidal currents (towards the 
Mediterranean Sea). In Fig. 1 are shown these largeamplitude internal waves in an initial stage of their generation (1a) and a little after the internal waves have been released (1b). The internal waves of Fig. 1a stand trapped by the supercritical flow over the sill during the outflow phase of tidal currents (Fig. 1e). On the other hand, Fig. 1b shows the same internal waves displaced to the east, once they have been released from Camarinal Sill around the beginning of the tidal current inflow (Fig. 1e).

The subinertial fluctuations in the flow through the Strait of Gibraltar have been related to the isostatic response of sea level variations to the atmospheric pressure fluctuations over the western Mediterranean (Crepon, 1965; Candela et al., 1989; García Lafuente et al., 2002). Also, subinertial flows are almost $180^{\circ}$ out of phase with respect to the atmospheric pressure fluctuations for oscillation periods ranging from 3 to 80 days.

The work of Pistek and La Violette (1999) is the only previous work concerning the relation between subinertial fluctuations and large-amplitude internal wave generation in the Strait of Gibraltar. These authors postulated that an increased subinertial flow towards the Atlantic, in
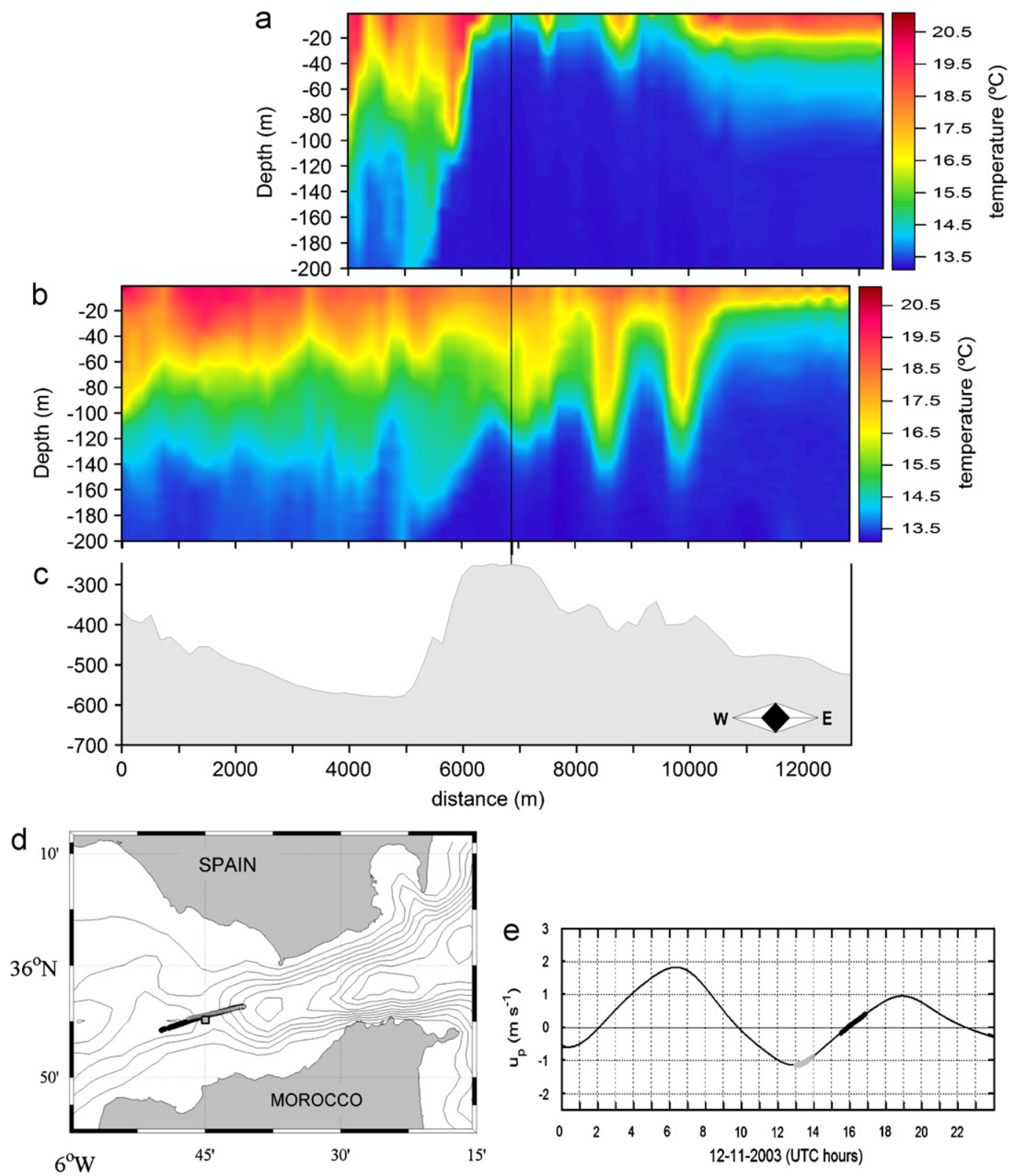

Fig. 1. Vertical sections of temperature (from XBTs records) in the along-strait direction, over Camarinal Sill, illustrating a large amplitude internal wave event that happened on day 2003-11-12, (a) in an initial stage of the internal wave generation and (b) a short time after internal waves were released from Camarinal Sill. In (c) bottom topography along the section is shown. The vertical black line crossing (a) and (b) indicate the location of ADCP and CTD moorings. (d) The location of the transects along which vertical sections were performed and (e) is the tidal current prediction over Camarinal Sill at $45 \mathrm{~m}$ depth during day 2003-11-12. The thicker portions of the curve indicate the time taken for doing the vertical sections. 
response to an increase in the atmospheric pressure, would cause the advection of internal waves westward, preventing the development and growth in amplitude of internal waves in the generation region (Camarinal Sill). However, this idea did not agree with their observations, which, to the contrary, showed that the interruption of the internal wave generation happened after a decrease in the atmospheric pressure over the western Mediterranean. In the following paragraphs we propose an explanation for that relationship.

\section{Observational background}

The observations consist of time series of currentvelocity and salinity recorded by moored ADCP and two CTD sensors located right over Camarinal Sill in a water column of about $280 \mathrm{~m}$ length. The sampling interval was $15 \mathrm{~min}$ for the ADCP and $10 \mathrm{~min}$ for the CTD. Those data were collected during the experiment "Strait 94-96", from October 1994 to 1996. The experiment was divided into four phases, each of them lasting about 6 months. Our analysis will be focussed on only two of those phases, which were chosen for two reasons: (i) the shallower conductivity sensor was located close to the sea surface

\section{a}
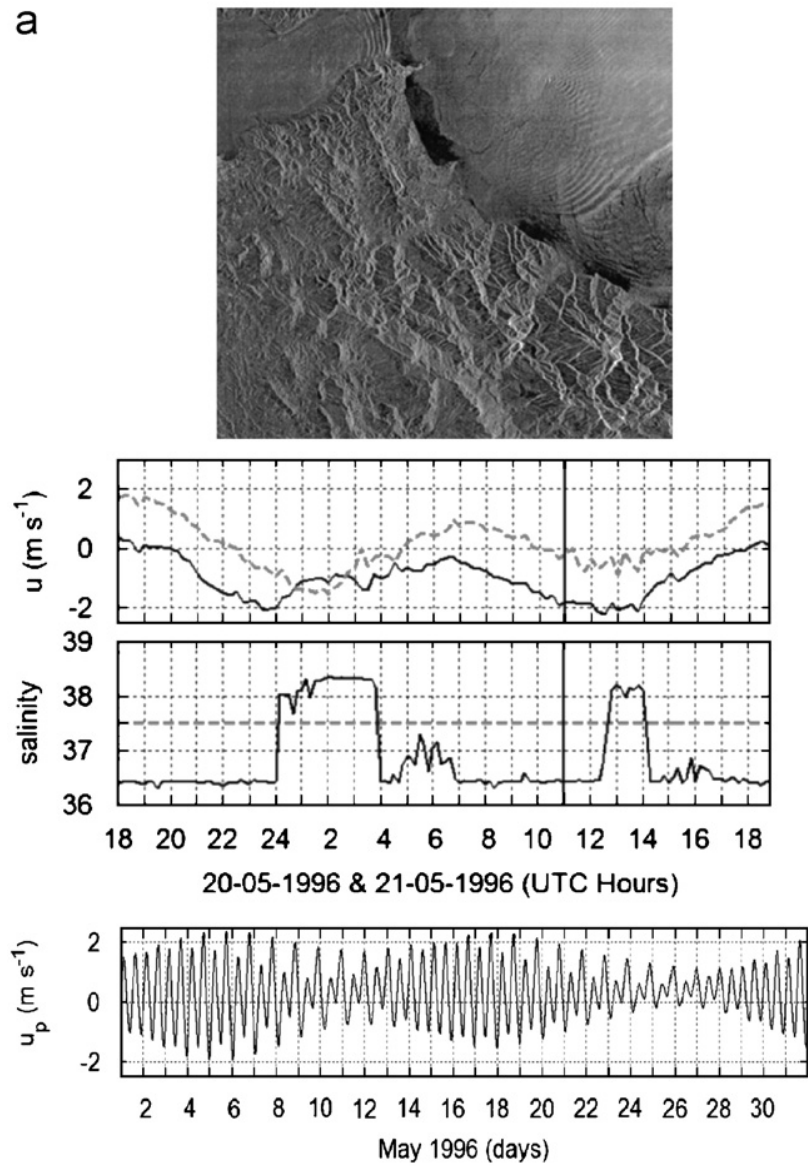

that allowed a record of large-amplitude internal wave events, which were able to produce large vertical displacement of isopycnal surfaces characterizing the Atlantic-Mediterranean interface and (ii) there were relatively long simultaneous records of current-velocity and salinity. In the two selected phases, the shallower CTD sensor was located at $50 \mathrm{~m}$ depth, while the ADCP was at $20 \mathrm{~m}$ from the bottom. It faced upward sampling of the water column with a vertical resolution of $10 \mathrm{~m}$ up to $45 \mathrm{~m}$ depth.

\subsection{Identification of internal wave signal in the recorded time series}

As shown in Fig. 2a, when a large-amplitude internal wave event is generated (SAR image of Fig. 2) a marked rise of the interface is seen at the mooring place, at the beginning of the outflow phase of tidal currents that is clearly identified as a very sharp increase in the salinity recorded by the shallower conductivity sensor (at $50 \mathrm{~m}$ depth). This signature of the salinity records over the sill resembles quite closely to those reported previously by Armi and Farmer (1988) and Richez (1994), who used

b
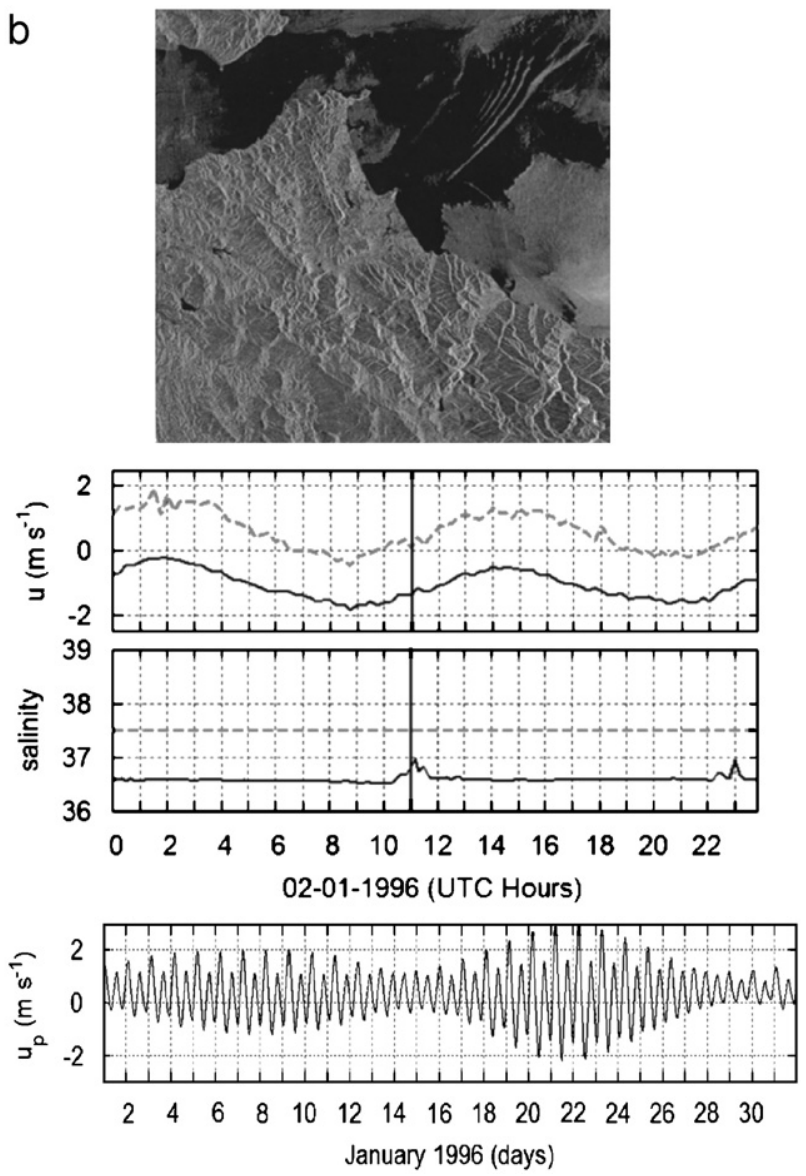

Fig. 2. Internal wave signals in the recorded variables over Camarinal Sill: (a) for a large-amplitude event and (b) for a moderate-amplitude event. At the top are shown the corresponding SAR images acquired by satellite ERS $2 . u$ is the current-velocity recorded by ADCP at $45 \mathrm{~m}$ (gray) and $255 \mathrm{~m}$ (black). $u_{\mathrm{p}}$ is the tidal current prediction in the corresponding month. 
them to detect large-amplitude internal waves generation and release from Camarinal Sill.

The velocity of the current in the upper and lower layer is affected by the rise of the interface, in the sense that when this rise occurs both velocities reach similar values (Fig. 2a). In that situation, large-amplitude internal waves are trapped over and on the lee side of the sill for about $4 \mathrm{~h}$. As described in the introduction, this trapping of the internal waves is produced by the prevailing critical conditions over the sill.

A little before the establishment of the inflow phase of the tidal current, the internal waves are released from Camarinal Sill toward the Mediterranean once conditions become subcritical. This is marked by a sharp decrease in the salinity values followed by some short-period oscillations (Fig. 2a).

Proceeding as explained above, during all the outflow phases of the measurement period two types of internal wave events were seen:

(i) Type I event: a very energetic process with large vertical displacement of isopycnals and intense perturbations in the velocity of the current and generated during spring tides, demanding critical conditions over the sill (Fig. 2a).

(ii) Type II event: a less energetic process that takes place during neap tides, showing moderate vertical displacements, less intensity in current-velocity perturbations and generally produced under subcritical conditions over the sill (Fig. 2b).

Type I events were present during about $28 \%$ of the total time of the experiment, Type II in 20\%; the remaining 52\% were situations when no large-amplitude internal wave signal was recorded. Also, 65\% of Type I events were present during spring tide conditions, while the remaining $35 \%$ were present during neap tides. Our analysis is focussed on Type I events, which are much more energetic and clearly identifiable in our salinity and ADCP records.

\subsection{Effect of subinertial flows on Type I internal wave generation}

At first glance, the analysis of the conditions under which the internal waves were generated seems to suggest that those episodes could be fairly well forecast from tidal current predictions through the water column or, for the sake of simplicity, the difference between the predicted tidal currents between upper and lower layers. Thus, when that difference is close to or less than zero a large-amplitude internal wave event would be expected to occur. Such tidal current predictions are obtained using the harmonic constants extracted from the application of least-squares harmonic analysis on a 6 month long ADCP record.

Although the analysis was extended to a 8 month period, for the sake of brevity and clarity only a fragment of the analyzed period, corresponding to 1996 February, is shown in Fig. 3. It must be noticed that subinertial flow oscillations during that period are about $180^{\circ}$ out of phase with respect to the atmospheric pressure fluctuations over the western Mediterranean. As can be seen, during the second spring tide, the large peaks in the salinity records identifying the occurrences of large-amplitude internal wave generation are in good agreement with the forecast based on the differences between upper and lower layer velocities. An outflow phase with a small velocity difference coincides with a large-amplitude internal wave event.

However, throughout the month we can find exceptions to that behavior. For instance, during 6-8 days, under spring tide conditions, our empirical model fails. In spite of the almost zero predicted differences between upper and lower velocities, large-amplitude internal waves are not generated as is evidenced by the absence of large peaks in the salinity records. During those days subinertial flow, in response to a decrease of atmospheric pressure over the western Mediterranean, is intensified towards the Mediterranean (positive sign), reaching a peak intensity in the along-strait current of $1 \mathrm{~m} / \mathrm{s}$. This situation favors the inflow and reduces the intensity of tidal currents during their outflow phase, a fact that seems to be related to the internal wave inhibition episodes.

On the other hand, during 11-12 days, the reverse situation is seen. During neap tide conditions, with a predicted difference between upper and lower velocities far from zero, large-amplitude internal wave generation seems to take place, as indicated by the large peaks in salinity. During those days, subinertial flow was directed toward the Atlantic (negative sign) with a peak velocity greater than $0.5 \mathrm{~m} / \mathrm{s}$. This situation increases the intensity of the tidal current during its outflow phase, which seems to favor the activation of large-amplitude internal wave generation episodes.

These episodes activated by subinertial flow seem to explain $35 \%$ of Type I events recorded during neap tides. The same episodes also explain the major part of the forecasting uncertainties since internal wave inhibition episodes were frequently much less, only 8 were observed during the whole analysis period.

The remaining task now is to find a physical explanation for these activation/inhibition phenomena during neap/spring tides related to subinertial flows. In the next section, we will deal with this subject.

\section{Physical mechanism}

A physical interpretation of the activation/inhibition by meteorologically forced subinertial flows of internal wave generation can be obtained by knowing hydraulic conditions over Camarinal Sill during the different outflow phases of the measurement period. In order to achieve this, it is worthwhile to consider the instantaneous internal Froude number, defined as (Hibiya, 1986)

$F(t)=\frac{c}{U(t)}$

where $U(t)$ is the velocity of total barotropic (tidal plus subinertial) flow and $c$ is the linear phase speed of the first baroclinic mode, which is equal to the greatest eigenvalue 


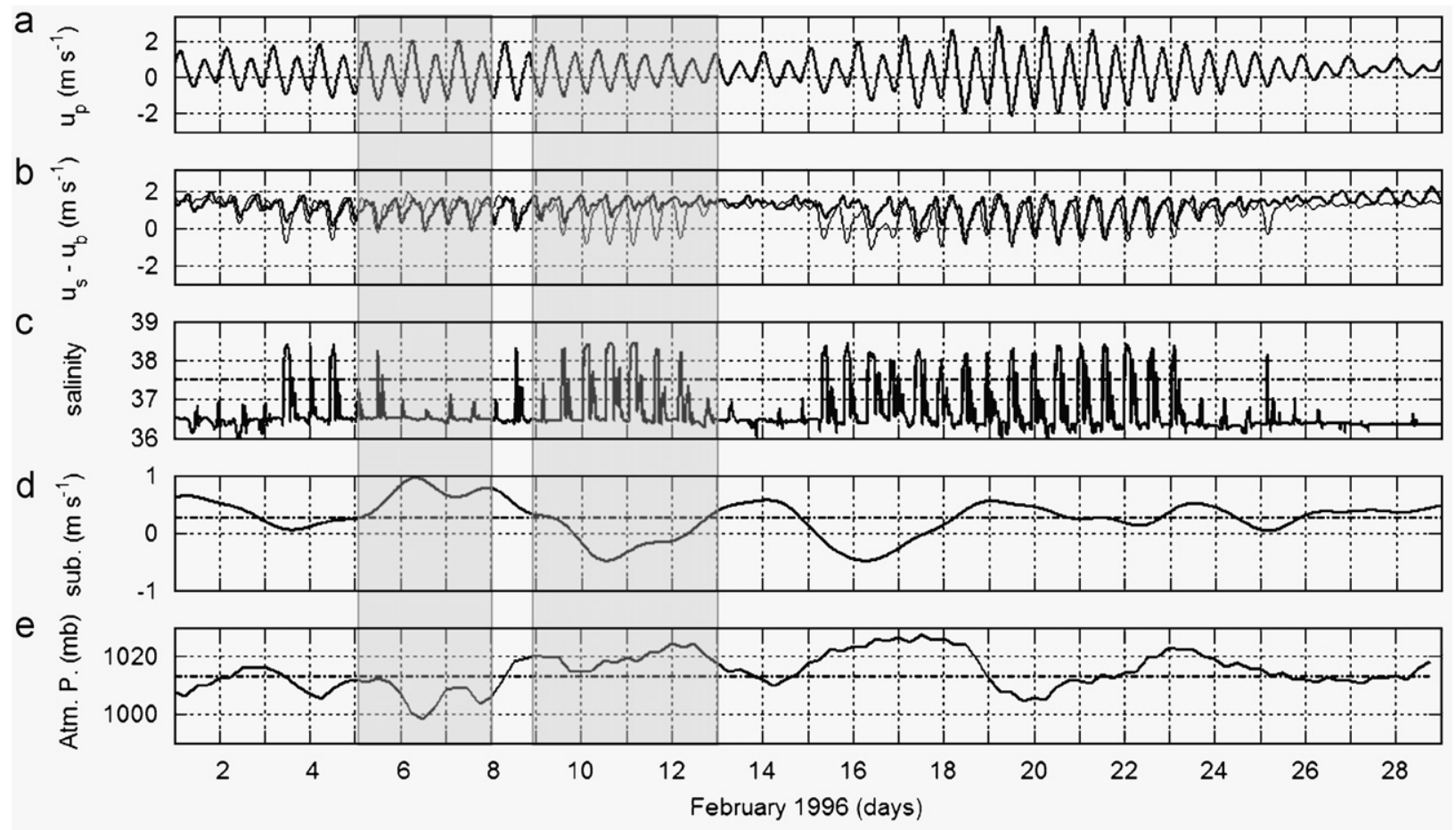

Fig. 3. Time series over Camarinal Sill during 1996 February: (a) tidal current prediction at $45 \mathrm{~m}$ depth, (b) differences between upper (45 $\mathrm{m}$ ) and lower $(255 \mathrm{~m}$ ) layer velocities, predicted (gray) and observed (black), (c) salinity at $50 \mathrm{~m}$ depth, (d) low pass filtered subinertial signal at $45 \mathrm{~m}$ depth, (e) atmospheric pressure in the western Alboran Sea. Shaded areas indicate the time intervals chosen to illustrate the investigated phenomena. Atmospheric pressure data were downloaded from the European Centre for Medium-Range Weather Forecast (ECMWF) web site.

of the Sturm-Liouville problem (Lee and Beardsley, 1974; Vlasenko et al., 2005)

$\frac{c^{2}}{N} \hat{\psi}_{z z}=\hat{\psi}$

$\hat{\psi}(x, z)$ being the amplitude of the stream function corresponding to the 2D problem disregarding earth rotation effects, with coordinates $x$ and $z$ oriented, respectively, in the along-strait direction and upward and $N(z)$ is the Brunt-Väisälä profile characterizing the background density field which was obtained using CTD measurements over Camarinal Sill from the MEDATLAS data base (MEDATLAS Consortium, 1997). Subscripts indicate partial derivatives with respect to the corresponding coordinate.

Fig. 4a and $\mathrm{b}$ shows the internal Froude number computations along two outflow phases, each corresponding with days February 5th and 6th, under spring tide conditions. During day 5, subinertial flow is around its monthly mean value (Fig. 3d). The background conditions are then characterized by a strong outflow, which imposes supercritical conditions over the sill. These supercritical conditions favor the trapping and amplification of the internal waves, which are able to grow by catching the kinetic energy supplied by the flow over and on the lee side of the sill (Farmer and Armi, 1999; Nakamura and Awaji, 2001). However, during the outflow of day 6, with the same tidal current background as the previous day but with an increased eastward subinertial flow (Fig. 3d), hydraulic conditions over the sill are drastically different. In this case, these conditions are subcritical because of the decrease in the total (tidal plus subinertial) barotropic outflow. In this situation, internal waves are no longer trapped or amplified, and generation of Type I events is inhibited.

On the other hand, Fig. $4 \mathrm{c}$ and $\mathrm{d}$ show similar computations during two outflow phases, each corresponding with days February 12 and 13, under neap tide conditions. During day 13 , subinertial flow is around its monthly mean value (Fig. 3d) and consequently, as expected, the existing weak outflow over the sill leads to subcritical conditions there. This fact does not favor the generation of Type I events. However, during outflow of day 12 , subinertial flow has been strongly increased in the westward direction. As a consequence, the increased total barotropic flow imposes critical conditions over the sill that favor the trapping and amplification of largeamplitude internal waves over and on the lee side of the sill. For the sake of brevity, we have only shown the analysis of those selected four events discussed above. The same analysis has been extended to the whole analysis period yielding identical results for all the identified activation/inhibition events.

As shown, increased subinertial flow towards the Atlantic is not able to separate internal waves from the lee side of the sill. This is because that although conditions over the sill were critical or supercritical, downstream of the sill flow decelerates, leading to subcritical conditions 

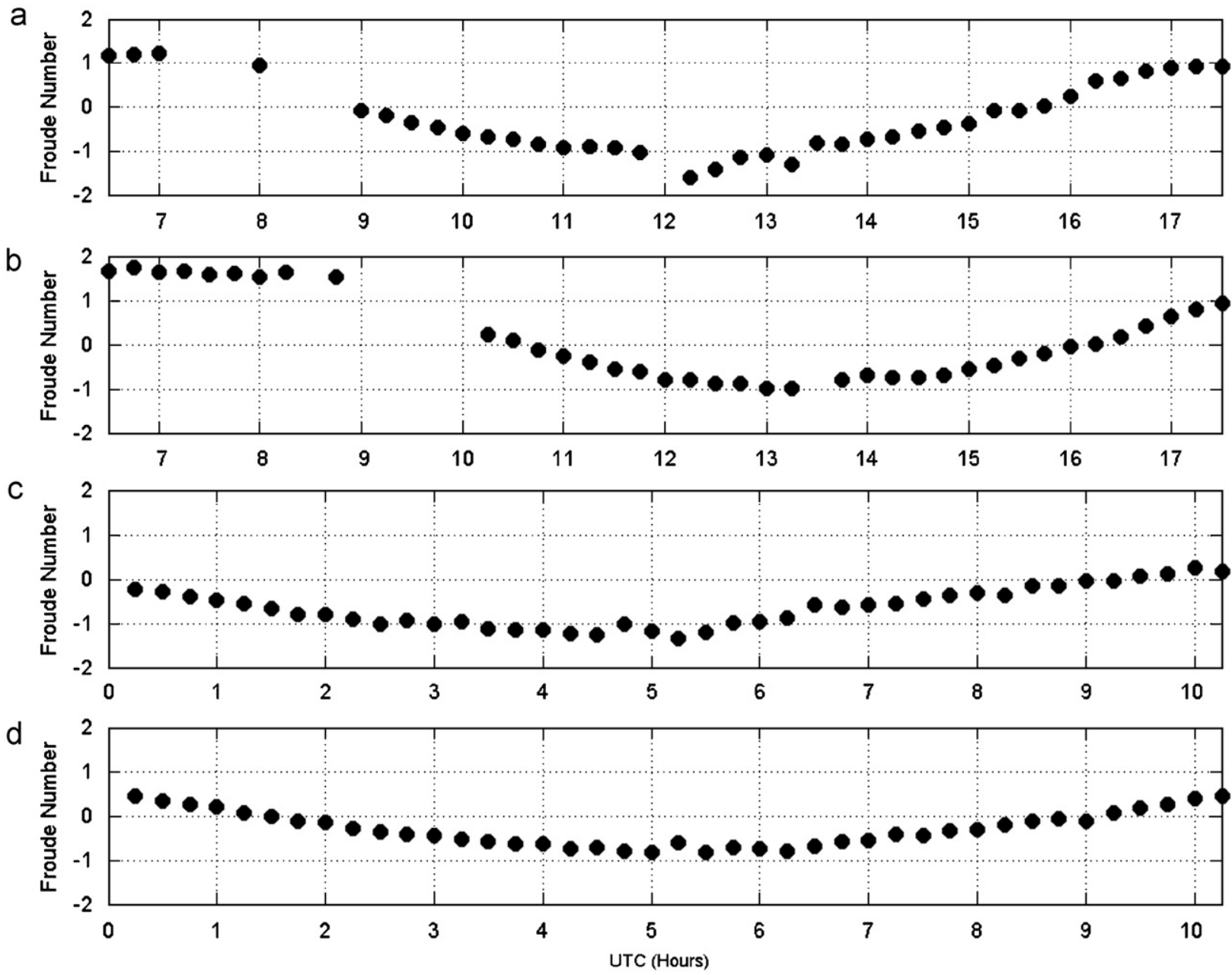

Fig. 4. Internal Froude number computations around the outflow phase of tidal current during February 1996 . The negative sign is an artefact to track the change of direction in the flow, positive (inflow) and negative (outflow). (a) and (b) Outflow phases on days 5 and 6 . (c) and (d) The same on days 12 and 13 .

here, which allows the internal waves to stand trapped on the eastern flank of the sill. This is the reason why, the mechanism proposed by Pistek and La Violette (1999), which related interruption of the internal wave generation with westward advection of the waves by an increased westward subinertial flow, did not agree with the observations.

\section{Conclusions}

From the analysis presented above, it may be concluded that modification of the hydraulic conditions over the sill produced by subinertial flow variations (forced by atmospheric pressure fluctuations in the western Mediterranean) is the mechanism responsible for the activation/inhibition of Type I internal wave events during neap/ spring tides. It is possible to active these internal wave events during neap tides, when hydraulic conditions over the sill do not favor their occurrences, and to inhibit their generation during spring tide conditions, when Type I internal wave events are expected to occur. This problem constitutes an interesting case study that illustrates the importance of considering the interaction between largeand small-scale phenomena to achieve full understanding of the dynamics of a given oceanographic region.

\section{Acknowledgments}

This study was carried out within Spanish project REN2001-2733-C02. We would like to thank Dr. Julio Candela for providing the data of the experiment "Strait 94-96". Atmospheric Pressure data were downloaded from the European Centre for Medium Range Weather Forecast (ECMWF) web site.

\section{References}

Armi, L., Farmer, D.M., 1988. The flow of Mediterranean water through the Strait of Gibraltar. Progress in Oceanography 21, 1-105. Bruno, M., Mañanes, R., Alonso, J.J., Izquierdo, A., Tejedor, L., Kagan, B. 2000. Vertical structure of the semidiurnal tidal currents at 
Camarinal Sill, the Strait of Gibraltar. Oceanologica Acta 23 (1), $15-24$.

Bruno, M., Alonso, J.J., Cózar, A., Vidal, J., Echevarría, F., Ruiz, J., RuizCañavate, 2002. The boiling water phenomena at Camarinal sill, the Strait of Gibraltar. Deep Sea Research II 49, 4097-4113.

Candela, J., Winant, C.D., Ruiz, A., 1989. Meteorologically forced subinertial flows trough the Strait of Gibraltar. Journal of Geophysical Research 94, 12667-12674.

Candela, J., Winant, C.D., Bryden, H.L., 1990. Tides in the strait of Gibraltar. Journal of Geophysical Research 95, 7317-7335.

Crepon, M., 1965. Influence de la presion armospherique sur le niveau moyén de la Mediterranée Occidentale el sur le flux á travers le Detroit de Gibraltar. Cah. Oceanography 1, 15-23.

Farmer, D., Armi, L., 1999. The generation and trapping of solitary waves over topography. Science 283, 188-190.

García Lafuente, J., Álvarez, E., Vargas, J.M., Ratsimandresy, W., 2002. Subinertial variability in the flow through the Strait of Gibraltar. Journal of Geophysical Research 107 (C10), 32.1-32.9.

Hibiya, T., 1986. Generation mechanism of internal waves by tidal flow over a sill. Journal of Geophysical Research 91, 7696-7708.

Lacombe, H., Richez, C., 1982. The regime of the Strait of Gibraltar. In: Nihoul, J.C.J. (Ed.), Hydrodynamics of Semi-Enclosed Seas. Elsevier Sci. Publ. Comp., New York, pp. 13-73.

Lee, C.Y., Beardsley, R.C., 1974. The generation of long nonlinear internal waves in a weakly stratified shear flow. Journal of Geophysical Research 79, 453-462.
Macias, D., Garcia, C.M., Echevarria, F., Vazquez, A., Bruno, M., 2006. Tidal-induced variability of mixing processes on Camarinal Sill (Strait of Gibraltar): a pulsating event. Journal of Marine Systems 60, 177-192.

MEDATLAS Consortium, 1997. Mediterranean Hydrographic Atlas, 3 CDROM and user Manual, MAS2-CT93-0074, IFREMER Ed.

Nakamura, T., Awaji, T., 2001. A growth mechanism for topographic internal waves generated by an oscillatory flow. Journal of Physical Oceanography 31, 2511-2524.

Pistek, P., La Violette, P.E., 1999. Observations of the suppression of tidegenerated nonlinear internal wave packets in the Strait of Gibraltar. Journal of Marine Systems 20, 113-128.

Richez, C., 1994. Airborne synthetic aperture radar tracking of internal waves in the Strait of Gibraltar. Progress in Oceanography 33, 93-159.

Vázquez, A., stashchuk, N., Vlasenko, V., Bruno, M., Izquierdo, A., Gallacher, P.C., 2006. Evidence of multimodal structure of the baroclinic tide in the Strait of Gibraltar. Geophysical Research Letters 33, L17605.

Vlasenko, V., Stashchuk, N., Hutter, K., 2005. Baroclinic Tides. Cambridge University Press, New York, pp. 351.

Wesson, J.C., Gregg, M.C., 1994. Mixing at Camarinal Sill in the Strait of Gibraltar. Journal of Geophysical Research 99, 9847-9878. 